\title{
Power spectral analysis of the electrocardiogram in diabetic children
}

\author{
M.D. Rollins ${ }^{1}$, J. G.Jenkins ${ }^{1}$, D.J.Carson ${ }^{1}$, B. G.McClure ${ }^{1}$, R.H. Mitchell ${ }^{2}$ and S.Z. Imam $^{2}$ \\ ${ }^{1}$ Royal Belfast Hospital for Sick Children, Department of Child Health, The Queen's University of Belfast and \\ ${ }^{2}$ Department of Electrical and Electronic Engineering, University of Ulster, Northern Ireland
}

\begin{abstract}
Summary. In recent years it has been shown that alteration in heart rate variability can be used for the objective assessment of autonomic function in adult diabetic patients. Using a microcomputer based system for on-line monitoring and analysis of heart rate variability by power spectral analysis, 100 children with Type 1 (insulin-dependent) diabetes mellitus were studied. A highly significant negative correlation was identified between heart rate variability and duration of diabetes $(r=-0.88, p<0.0001)$. The mean heart rate variability in patients with diabetes of duration 3 years or more was significantly lower in comparison to age-matched control subjects. A highly significant negative correlation was evi-
\end{abstract}

dent between heart rate variability and mean $\mathrm{HbA}_{1}$ in patients with duration of diabetes of 5 years or more. A mean $\mathrm{HbA}_{1}$ over $10 \%$ during this period was associated with the greatest reduction in heart rate variability. Serial measurements of heart rate variability in diabetic children may be of predictive value prior to the onset of symptomatic neuropathy.

Key words: Type 1 (insulin-dependent) diabetes mellitus, autonomic neuropathy, heart rate variability, power spectral analysis, electrocardiogram.
Measurable autonomic defects affect as many as one sixth of all diabetic patients [1]. Those patients who are symptomatic have a poor prognosis with up to $50 \%$ dying within 5 years $[2,3]$. Quantitative bedside tests for measuring autonomic function have been available for nearly 20 years $[4,5]$ and of these the measurement of variability in heart rate remains a sensitive reproducible and specific test [6]. Previous studies in adult diabetes mellitus have shown a reduction in heart rate variability (HRV) in both symptomatic and asymptomatic autonomic neuropathy $[7,8]$. Studies of HRV in diabetic children and adolescents have been few as it is felt that clinical neuropathy occurs infrequently [9]. Gruneklee et al. did however find a reduction in HRV in children with clinical evidence of neuropathy [10]. The present battery of cardiovascular function tests to detect early neuropathic changes are unsuitable in a childhood population as they are invasive or complex $[11,12]$.

For this reason we have developed a microcomputerbased system for on-line monitoring and analysis of HRV using power spectral analysis [13-17] (Fig.1). Similar techniques in adult diabetic patients have shown a reduction in HRV in patients with autonomic neuropathy compared to healthy control subjects $[14-16,18,19]$.

In a pilot study involving 30 children and adolescents aged 9-16 years, a reduction in HRV with increasing du- ration of diabetes was noted. Poor diabetic control also appeared to be associated with a similar reduction in HRV [20]. These findings prompted us to investigate whether autonomic dysfunction exists in a larger group of children with diabetes, and, if so, is it related to the duration of diabetes and/or the degree of glycaemic control?

\section{Subjects and methods}

Between November 1988 and June 1989, 100 consecutive children and adolescents ( 48 girls) aged between 2 and 17 (mean 11.1) years were studied while attending the diabetic clinic in the Royal Belfast Hospital for Sick Children. Their duration of diabetes ranged from $0.5-15$ (mean 5.2) years. Prior to performing HRV studies each child had a full clinical assessment. Blood pressure was recorded in the standing and lying position using a Hawksley random zero sphygmomanometer. Neurological symptoms and disability scores as devised by Dyck were calculated for each patient [21]. This scoring system detects and grades the severity of neuropathy based on evaluation of neurological symptoms using a neurological symptom score and evaluation of neurological signs using a neurological disability score. It includes a questionnaire on the presence or absence of differing symptoms including grades of muscle weakness, sensory disturbances and autonomic symptoms. A clinical assessment of the neurological system is then made to detect the presence of defects affecting the peripheral nervous system. Examination of the fundi was performed on each subject to detect the presence of retinopathy. Fol- 


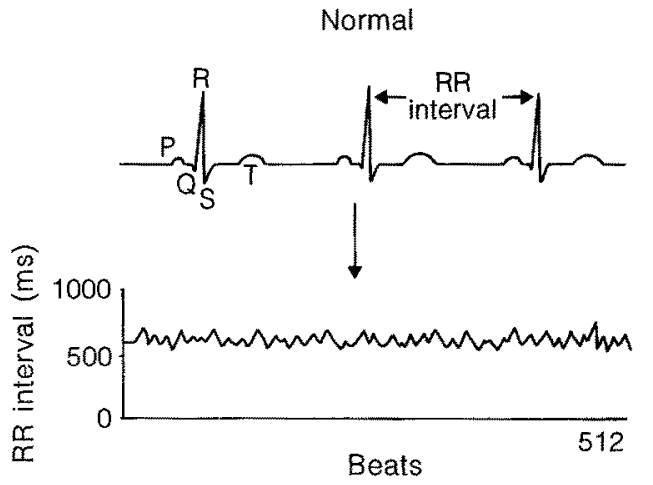

lowing informed parental consent the HRV was recorded while the patient was resting in the supine position over a $10 \mathrm{~min}$ period. The ECG was recorded using a Corometrics 505 cardiorespiratory monitor (Corometrics Medical Systems Inc., Wallingford, Conn., USA), and transferred directly onto a portable device [13].

The heart rate signal was obtained from an output terminal at the rear of the monitor and fed into a microprocessor-based recording system. The data retrieval system timed, displayed and saved the heart rate information in random access memory. The data was then transferred to an Apple-based microcomputer for display, analysis and storage on magnetic disk. The ECG signal entering the data retrieval system was filtered to remove interference and the $R$ peak of the ECG detected using an analogue detection method [22]. The R$R$ interval was measured to an accuracy of $0.1 \mathrm{~ms}$. A sample consisting of 512 consecutive R-R intervals was selected from the children's heart rate recordings. In the study this amounted to a recording period of between 3 and 7 mins depending on the individual patient's heart rate. To obtain an artefact-free sample no patient required a total ECG recording time of greater than $10 \mathrm{~min}$. The power spectrum was evaluated using a 256-point fast Fourier transform routine and implemented on the Apple microcomputer. The average power spectrum provides a pictorial representation of the variations of the heart rate signal [23].

A measure of spectral power has been developed which represents the overall variability present in the heart rate signal in the frequency range $0.01-0.2 \mathrm{~Hz}$. Other bands have been studied previously and this frequency range has proved to be the most discriminative for clinical prediction $[17,24]$. Most activity is below $0.1 \mathrm{~Hz}$ with a strong peak at $0.05 \mathrm{~Hz}$ (Fig. 2). This includes the dominant spectral component observed around $0.1 \mathrm{~Hz}$ (Mayer waves) which is felt to represent baroreceptor activity [25]. Other spectral components including those related to respiratory arrhythmia $(0.25 \mathrm{~Hz})$ which could previously have influenced the interpretation of the R-R interval are hence excluded. Measurement of the area under the spectral plot quantifies the HRV. Spectral power is a measure of the square of the amplitude of the fluctuations of the heart rate $\left(\mathrm{S}^{2} / \mathrm{Hz}\right)$ divided by 1,000 for clarity of presentation.

Immediately following the HRV measurement a blood sample was taken for random plasma glucose and $\mathrm{HbA}_{1}$. Consecutive $\mathrm{HbA}_{1}$ measurements were documented every 3 months from the diagnosis of diabetes and a mean $\mathrm{HbA}_{1}$ value for each patient was estimated over this period. The control group consisted of 50 children matched for age and sex who also had a full clinical assessment as well as HRV measurement performed. These children had been admitted to hospital for minor elective surgery or were convalescing after minor surgery. None had any known medical history or intercurrent illness. The protocol received ethical committee approval.

\section{Statistical analysis}

The results are expressed as mean $\pm 1 \mathrm{SD}$. Linear regression analysis was used to describe the relation between the diabetic parameters and power spectra. Statistical significance was analysed by the Student's $t$-test. $p<0.05$ was considered significant.
Adult diabetic
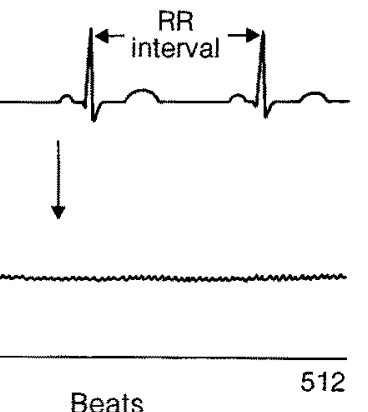

Fig. 1. Heart rate plot of 512 R-R beats in healthy control and adult diabetic subjects

\section{Results}

None of the diabetic children studied showed any evidence of neurological impairment with symptom scores $<4$ (median patient score $=2$, control score $=1$, NS by Mann-Whitney $U$ test) and no signs of peripheral or autonomic neuropathy [21]. There was no evidence of postural hypotension (a fall in systolic blood pressure of more than $20 \mathrm{~mm} \mathrm{Hg}$ on standing), in either the study or control group. Age-related blood pressure recordings were also not significantly different between either group. None of
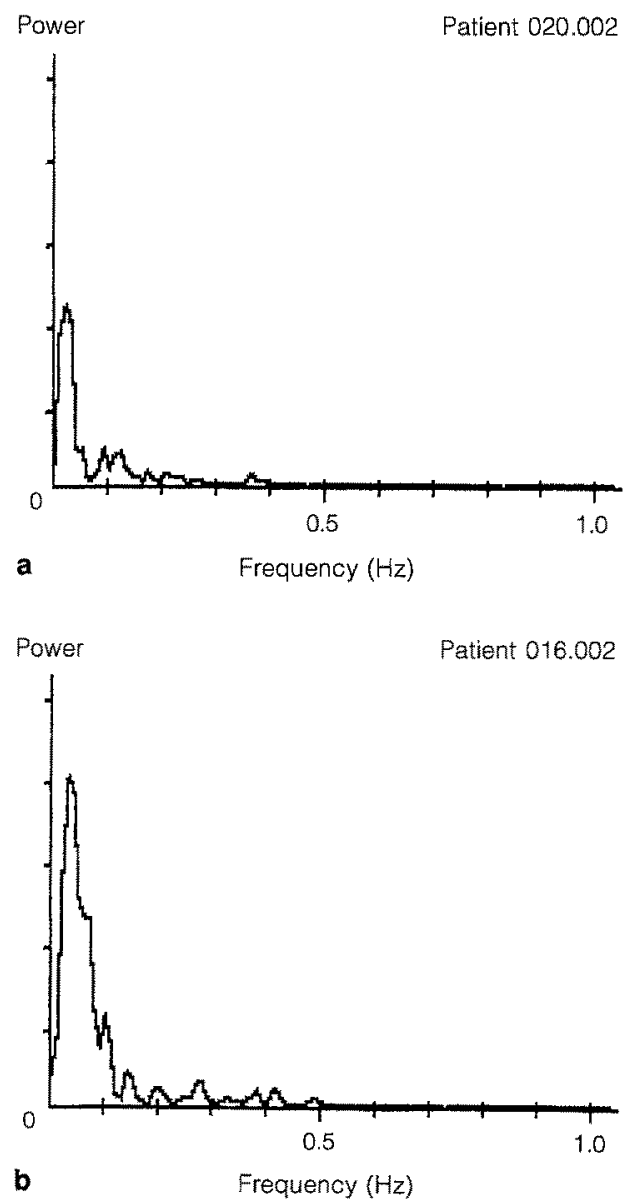

Fig. 2. Pictorial representation of power spectral plot in healthy control (top panel) and diabetic patient (bottom panel) with autonomic neuropathy. The area under the curve represents spectral power $\left(\mathrm{S}^{2} / \mathrm{Hz}\right)$ and is markedly reduced in the patient 


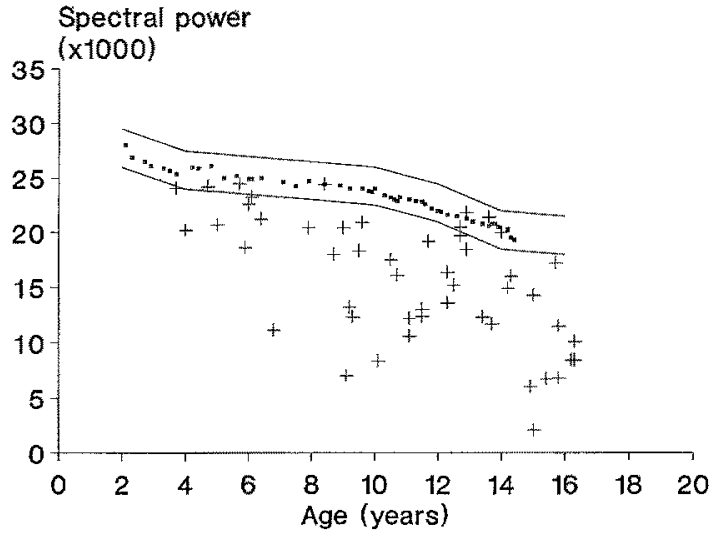

Fig.3. Power spectral values for diabetic children $(+)$ in relation to age, compared with the $95 \%$ confidence limits for values obtained in control subjects (

the patients studied showed evidence of retinopathy on funduscopic examination. There was no significant difference between resting heart rates measured in either study or control group.

In the control group HRV diminished slightly with increasing age (Fig, 3). The mean value for all control subjects was $23.4 \pm 4.3$. The majority of diabetic patients had lower values of HRV than age-matched control subjects (being below the $95 \%$ confidence limits).

In the study group HRV was reduced with increasing duration of disease $(r=-0.88, p<0.0001)$ (Fig. 4). The mean HRV in patients with diabetes of less than 3 years was not significantly different from age-matched control subjects $(22.5 \pm 2.0$ vs $23.4 \pm 4.3)$. With a duration of diabetes of 3 years or more, significant reduction in HRV was present $(13.4 \pm 3.6 \mathrm{vs} 23.4 \pm 4.3, p<0.05)$. Multiple regression analysis demonstrates that the effect of duration of diabetes on HRV is much greater $(p<0.0001)$ than that of age which is not statistically significant $(p=0.62)$.

On comparing HRV with control of diabetes as indicated by mean $\mathrm{HbA}_{1}$, a fall in HRV was evident with worsening control $(r=-0.47, p<0.001)$. This became even more significant in patients with duration of diabetes of 5 years or more $(r=-0.81, p<0.0001)$ (Fig. 5). The lowest values of power were found in those children with diabetes present for more than 5 years and mean $\mathrm{HbA}_{1}$ greater than $10 \%$ (Fig. 6). There was no correlation between HRV and random blood glucose taken at the time of the recording.

\section{Discussion}

Diabetic autonomic neuropathy is generally thought to be a late complication because it is only detected in patients with diabetes of long duration. As newer techniques to test autonomic function have been developed it has become clear that autonomic nervous dysfunction is present much earlier in the course of diabetes. Current studies have centred on impairment of various cardiovascular reflexes, but they have involved manual measurements of physiological parameters and required active co-operation of the patient. Alterations in HRV can be used for the objective assessment of autonomic function and is known to precede the development of symptoms in the adult $[18,19]$. This may also be the case in children with diabetes even though neuropathy is generally unrecognised in this age group. A non-invasive approach with no active patient co-operation is obviously preferable in childhood. Spectral analysis of beat-beat R-R interval variations on a continuous ECG fulfils this criteria. We found the measurement of HRV in both study and control groups easy to perform in children. The degree of co-operation of the patient resting in the supine position during the procedure was very high even in the pre-school age group. Obtaining an artefact-free recording of 512 successive (R-R) beats required for the analysis was not difficult.

Our results confirm a reduction in $\mathrm{HRV}$ with increasing duration of diabetes as has previously been reported from our pilot study [20], and which is now well-documented in adult diabetic patients $[14-16,18,19]$. The reduction in HRV reaches statistical significance after a period of only 3 years. Multiple regression analysis reveals that duration of diabetes has a highly significant effect on HRV compared to age, confirming that the marked fall in HRV is not related to increasing age. Gruneklee et al., using traditional methods for the measurement of HRV, found reduced levels only in those children with clinical evidence of neuropathy, suggesting that a decrease in HRV correlates with the presence of neuropathy but does not precede it [10]. Our results using spectral analysis have the sensitivity required to detect alterations in HRV prior to the onset of clinically demonstrable autonomic neuropathy. Although powerspectral analysis of the ECGisstill a research tool for the detection of autonomic dysfunction in the adult diabetic patient, its application in a childhood population has distinct advantages over the existing cardiovascular tests of autonomic function in that it is less invasive, less time consuming, and less upsetting for the young patient.

In this study a reduction in HRV is also noted with worsening control of diabetes as depicted by serial measurements of mean $\mathrm{HbA}_{1}$ over this period. The lowest levels of HRV are seen with duration of diabetes of 5 years or more and $\mathrm{HbA}_{1}$ over $10 \%$. In order to test the reliability and sensitivity of this technique we are currently performing HRV studies in an adult diabetic population, comparing diabetic patients with established clinical neuropathy to healthy control subjects. Follow-up studies will determine

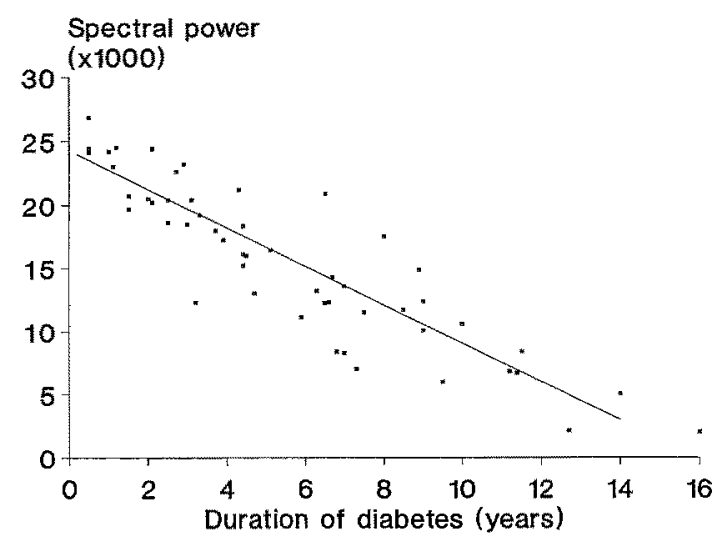

Fig. 4. The relationship between heart rate variability and duration of diabetes 


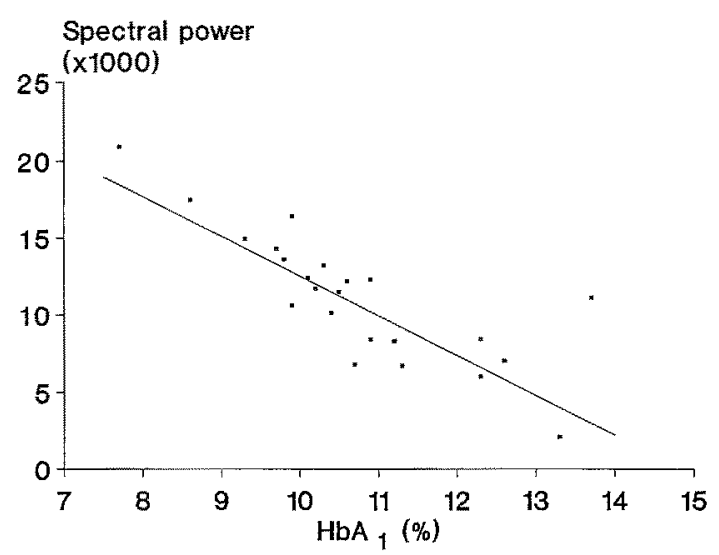

Fig.5. The relationship between heart rate variability and mean $\mathrm{HbA}_{1}$ in patients with diabetes for 5 years or more

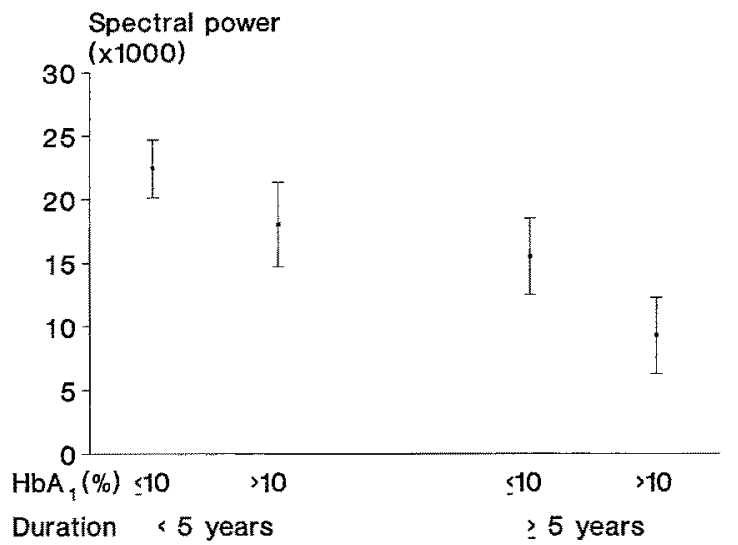

Fig.6. Summary of heart rate variability findings in control and patient groups

if changes in HRV are predictive of the subsequent development of autonomic neuropathy and whether a reduction in HRV can be reversed by improving glycaemic control. Unlike traditional techniques for detection of autonomic neuropathy, this method allows serial monitoring of HRV during routine clinic visits, is easy to perform and actively enjoyed by the children.

Acknowledgements. The authors would like to thank Miss L. Thompson for typing the manuscript.

\section{References}

1. O'Brien IAD, O'Hare JP, Lewin IG, Corrall RJM (1986) The prevalence of autonomic neuropathy in insulin-dependent diabetes mellitus: a controlled study based on heart rate variability. QJ Med 61: 957-967

2. Ewing DJ, Campbell IW, Clarke BF (1980) The natural history of diabetic autonomic neuropathy. Q J Med 49:95-108

3. Watkins PJ (1990) Diabetic autonomic neuropathy. N Engl J Med 322: 1078-1079

4. Pfeifer MA, Peterson H (1987) Cardiovascular autonomic neuropathy. In: Dyck PJ, Thomas PK, Asbury AK, Winegrad AI, Porte D (eds) Diabetic neuropathy. Saunders, Philadelphia, pp. $122-133$

5. Ewing DJ (1988) Recent advances in the non-invasive investigation of diabetic autonomic neuropathy. In: Bannister $\mathrm{R}$ (ed) $\mathrm{Au}-$ tonomic failure: a textbook of clinical disorders of the autonomic nervous system, 2nd ed. Oxford University Press, New York, pp. $667-689$
6. Wheeler T, Watkins PJ (1973) Cardiac denervation in diabeties. BrMed J 4:584-586

7. Gunderson HJG, Neubauer B (1977) A long-term diabetic autonomic nervous neuropathy. Diabetologia 13: 137-140

8. Hilsted J, Jensen SB (1979) A simple test for autonomic neuropathy in juvenile diabetes. Acta Med Scand 205: 385-387

9. Boulton AJM, Knight G, Dury J, Ward JD (1985) The prevalence of symptomatic diabetic neuropathy in an insulintreated population. Diab Care 8: 125-128

10. Gruneklee D, Cicmir I, Morguet A, Wendel U, Bremer HJ (1981) Studies of beat-to-beat heart rate variation in resting diabetic children. Pediatr Adolesc Endocr 9:255-259

11. Ewing DJ, Clarke BF (1982) Diagnosis and management of diabetic autonomic neuropathy. Br Med J 285: 916-918

12. Bennet T, Farquhar IK (1978) Assessment of methods for estimating autonomic nervous control of heart in patients with diabetes mellitus. Diabetes 27:1167-1174

13. Jenkins JG, Mitchell RH, McClure BG, Ritchie JWK, McCready $P(1986)$ The use of a microcomputer for on-line analysis of heart rate variability in newborn infants. Rolfe, 2nd International Conference on foetal and neonatal physiological measurements, $\mathrm{Ox}$ ford 1984, Part 2. Neonatal physiological measurements. Butterworths, London, pp. 49-55

14. Lishner M, Akselrod S, Mor Avi V, Oz O, Divon M, Ravid M (1987) Spectral analysis of heart rate fluctuations: a non invasive sensitive method for early diagnosis of autonomic neuropathy in diabetes mellitus. J Autonom Nerv System 19: 119-125

15. Weise F, Heidenreich $F$, Runge U (1988) Heart rate fluctuations in diabetic patients with cardiac vagal dysfunction: a spectral analysis. Diab Med 5: 324-327

16. Pagani M, Malfatto G, Pienni S et al. (1989) Spectral analysis of heart rate variability in the assessment of autonomic diabetic neuropathy. J Auton Nerv Syst 23: 143-153

17. Sharif BS, Mitchell RH, Cahill S, Jenkins JG, McClure BG (1989) A spectral index to represent heart rate variability in neonates. Automedica 12: 75-89

18. Bellavere $F$, Thomaseth $\mathrm{K}$, Cobelli $\mathrm{C}$ et al. (1989) Evaluation of the vagal-sympathetic interaction in diabetics with autonomic neuropathy through power spectrum density analysis of the heart rate. A critical revision of the natural history of diabetic autonomic neuropathy is possible. Functional Neurology 4:177-181

19. Lanting P, Faes TJC, Heimans JJ, ten Voorde BJ, Nauta JJP, Rompelman O (1990) Spectral analysis of spontaneous heart rate variation in diabetic patients. Diab Med 7: 705-710

20. Jenkins JG, Carson DJ, McClure BG, Sharif B, McCready P, Mitchell RH (1989) Heart rate variability in young diabetics. Prognosis of diabetesinchildren. Pediatr AdolescEndocrinol 18:42-46

21. Dyck PJ, Sherman WR, Hallcher LM, et al. (1980) Human diabetic endoneurial sorbitol, fructose and myo-inositol related to serial nerve morphometry. Ann Neurol 8: 590-596

22. Cahill SI, McClure G (1983) A microcomputer-based heart rate variability monitor. IEEE Trans Biomed Eng 30: 87-93

23. Akselrod S, Gordon D, Madwed JB, Snidman NC, Shannon DC, Cohen RJ (1985) Haemodynamic regulation: investigation by spectral analysis. Am J Physiol 249: H867-H875

24. Fogarty PP, Dornan JC (1990) Computerized spectral analysis of heart rate variability in labour. Contemp Rev Obstet Gynaecol 2: 69-74

25. Penaz J (1978) Mayer waves: history and methodology. Automedica 2: 135-141

Received: 3 May 1991

and in final revised form: 27 December 1991

Dr. M.D. Rollins

Department of Child Health

Institute of Clinical Science

Grosvenor Road

Belfast BT12 6BJ

Northern Ireland

UK 